\section{Survey of Arbuscular Mycorrhizal Fungal Communities in Northern California Vineyards and Mycorrhizal Colonization Potential of Grapevine Nursery Stock}

\author{
Xiaomei Cheng \\ Sustainable Agriculture Research and Education Program, University of \\ California, Davis, CA 95616
}

Kendra Baumgartner ${ }^{1}$

U.S. Department of Agriculture, Agricultural Research Service, Department of Plant Pathology, University of California, Davis, CA 95616

Additional index words. fungal community, mycorrhizae, root colonization, rootstock, soil fumigation, Vitis vinifera

Abstract. Indigenous arbuscular mycorrhizal (AM) fungal communities were characterized by examining spores in five fumigated and five nonfumigated vineyards in Northern California. None of the vineyards surveyed lacked spores, but species composition differed among the vineyards. Most of the fungi were in the genus Glomus; Paraglomus occultum Morton \& Redecker, G. etunicatum Becker \& Gerd., and G. aggregatum Schenck \& Smith emend. Koske were the most common species identified. Fungal diversity was greater in nonfumigated than in fumigated vineyards. Field-propagated grapevine nursery stock was examined as a potential source of $\mathrm{AM}$ fungi for fumigated vineyards. We quantified fungal colonization of new roots initiated from field-grown benchgrafts and potted benchgrafts of Cabernet Sauvignon on three rootstocks (101-14, 110R, and St. George). After 7 months of growth in the greenhouse, new roots initiated from dormant roots of field-grown and potted benchgrafts were colonized by AM fungi. Mycorrhizal colonization of new roots of field-grown benchgrafts was significantly higher than that of potted benchgrafts. Our results suggest that field-propagated nursery stock can serve as a source of AM fungi and may be better suited for fumigated and/or low phosphorus soils than potted benchgrafts. with soilborne pathogens such as Meloidogyne incognita (Kofoid \& White) Chitwood (rootknot nematode), Xiphinema index Thorne \& Allen (dagger nematode), and Armillaria mellea (Vahl:Fr.) Kummer (oak root fungus). Soil fumigation is necessary to kill soilborne pathogens, but fumigants are also detrimental to populations of beneficial microbes including mycorrhizal fungi (Menge, 1982).

Mycorrhizal colonization is important for young grapevines to establish and survive in fumigated soil (Menge et al., 1983). Arbuscular mycorrhizal (AM) fungal species vary in their efficiency of colonizing grapevine roots (Biricolti et al., 1997, Linderman and Davis, 2001). Greenhouse experiments have shown that inoculation with some AM fungal species is associated with a positive growth response, while others seem to have no effect on growth (Biricolti et al., 1997; Linderman and Davis, 2001; Schubert et al., 1988). Soil fumigation does not destroy $100 \%$ of the AM fungal inoculum in the soil (Menge, 1982). However, it may decrease the diversity of AM fungal species to the extent that efficient colonizers of grapevine roots are eliminated from the AM fungal community. It may also decrease the chances of grapevine roots encountering the most beneficial combination of AM fungal species.

The long-term effects of soil fumigation on diversity of AM fungi in California vineyards are not known. Fumigant-induced shifts in the AM fungal community may have important consequences with respect to colonization of

Fig. 1. Northern California vineyards examined in this study. Dots represent locations of individual vineyards. $\mathrm{M}=$ Mendocino County, $\mathrm{N}=$ Napa County, S = San Joaquin County, and So = Sonoma County.
Grapevines have been reported to form arbuscular mycorrhizal (AM) symbioses in grape-growing regions worldwide (Deal et al., 1972; Karagiannidis et al., 1997; Menge et al., 1983; Nappi et al., 1985; Possingham and Groot-Obbink, 1971). Past research showed that AM fungal inoculation of grapevines enhanced shoot and root growth (Biricolti et al., 1997; Linderman and Davis, 2001; Schubert et al., 1988), increased tissue phosphorus (P) concentration (Biricolti et al., 1997; Karagiannidis et al., 1997), increased lateral root number and total root length (Schellenbaum et al., 1991), and protected grapevines from the potential toxicity caused by lead $(\mathrm{Pb})$ and cadmium $(\mathrm{Cd})$ (Karagiannidis and Nikolaou, 2000).

Before planting new vineyards or replanting existing vineyards in California soil, fumigants are often used to treat soil infested

Received for publication 6 Nov. 2003. Accepted for publication 22 Mar. 2004. This research was supported by the USDA-ARS and the American Vineyard Foundation. We thank Jeremy Warren and Sharon Schnabel for field and laboratory assistance. Special thanks to Louise Egerton-Warburton for helping with arbuscular mycorrhizal fungi identification.

${ }^{1}$ To whom reprint request should be addressed; email kbaumgartner@ucdavis.edu.

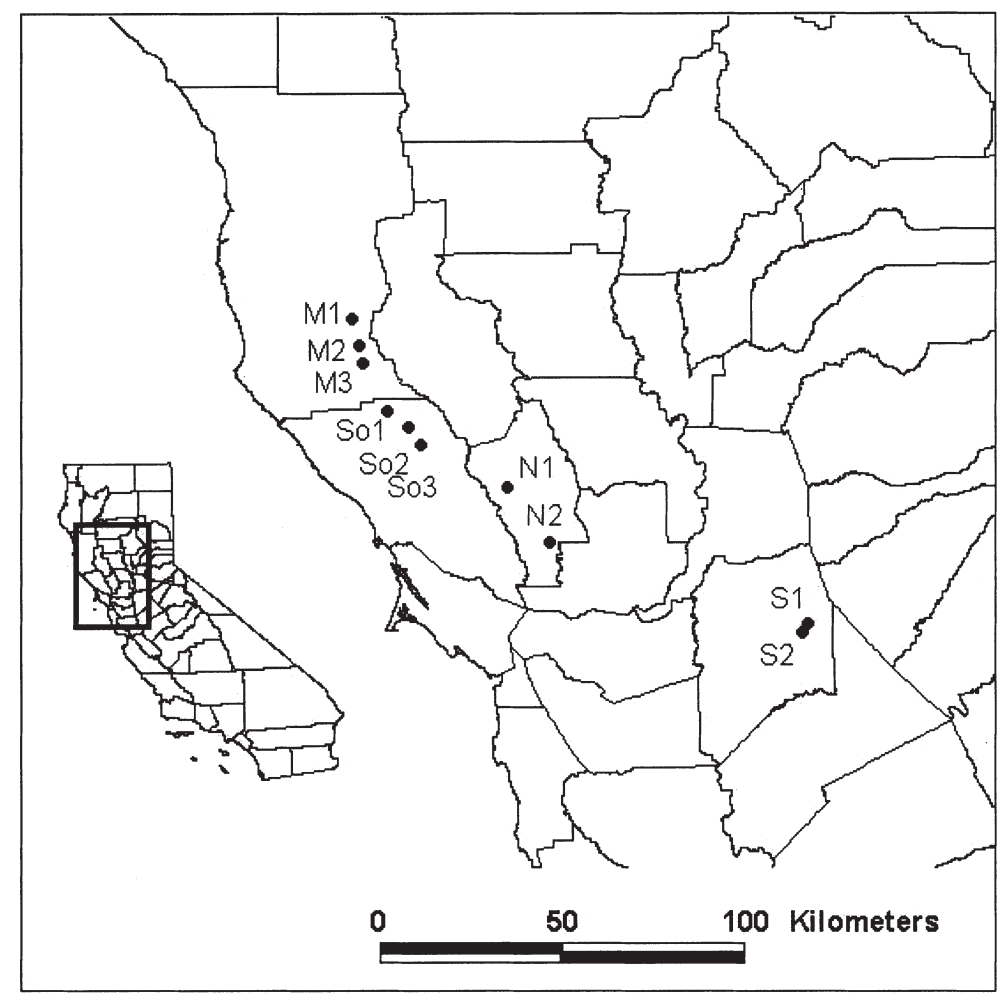


Table 1. Grapevine cultivars and rootstocks planted in northern California vineyards examined in this study.

\begin{tabular}{lcc}
\hline Vineyard & Vitis vinifera cultivar & Rootstock \\
\hline Mendocino-1 & Chardonnay & O39-16 \\
Mendocino-2 & Sauvignon Blanc & $101-14$ \\
Mendocino-3 & Roussanne & SO4 \\
Napa-1 & Cabernet Sauvignon & $3309 \mathrm{C}$ \\
Napa-2 & Cabernet Sauvignon & $3309 \mathrm{C}$ \\
San Joaquin 1 & Cabernet Sauvignon & $3309 \mathrm{C}$ \\
San Joaquin 2 & Merlot & $5 \mathrm{BB}$ \\
Sonoma-1 & Cabernet Sauvignon & $1103 \mathrm{P}$ \\
Sonoma-2 & Malbec & $101-14 \mathrm{Mgt}$ \\
Sonoma-3 & Sauvignon Blanc & O39-16 \\
\hline
\end{tabular}

grapevines immediately after planting and at later stages of grapevine growth. A diverse AM fungal community may be more capable of providing grapevines with consistent benefits across a broad range of soil conditions, as has been demonstrated in other crops (Daft and Hogarth, 1983; Koomen et al., 1987). Describing AM fungal community diversity in fumigated and nonfumigated vineyards is an important first step toward addressing the effects of soil fumigation on indigenous AM fungal communities.

Grapevine nursery stock may serve as an important source of AM fungi in fumigated vineyards, in addition to the few AM fungal propagules that survive fumigation and windblown spores from adjacent fields. In California grapevine nurseries, the most common form of plant material is the benchgraft, which is propagated from hardwood cuttings taken from dormant canes of scion and rootstock. After grafting, they are rooted either in fumigated field soil in an open-ground nursery (referred to as field-grown benchgrafts) or in sterile potting mix in pots kept outdoors (referred to as potted benchgrafts). Both types of benchgrafts are rooted in media that is initially free of AM fungal inoculum, but the approximately 7 months they spend growing in the field may be sufficient time for wind-blown AM fungal spores to colonize their roots or for roots to reach AM propagules below the fumigant level.

Although methyl bromide will eventually be banned for use in California, other fumigants will remain available and the practice of soil fumigation will continue. Knowledge of the long-term effects of soil fumigation on the AM fungal community may help us understand the role that AM fungi play in grapevine health. Evaluating grapevine nursery stock as a potential source of AM fungi may provide grape-growers with an alternative to applying costly commercial inoculum to vineyards planted in fumigated soil. The objectives of this research were to 1) characterize the AM fungal community on grapevine roots from fumigated and nonfumigated vineyards in Northern California, and 2) evaluate grapevine nursery stock as a potential source of AM fungal inoculum for new vineyards.

\section{Materials and Methods}

Survey of AM fungal communities in fumigated and nonfumigated vineyards

In October 2001, we conducted a survey of AM fungi in 10 northern California vineyards located in four counties: Mendocino(M), Napa (N), San Joaquin (S), and Sonoma (So) (Fig. 1). Of these vineyards, five were fumigated (M1, N1, So1, So2, So3) and five were nonfumigated (M2, M3, N2, S1, S2). All vineyards were 4 months to 2 years old. They were planted with several different varieties of Vitis vinifera $\mathrm{L}$. grafted to different phylloxera-resistant rootstocks (Table 1). Methyl bromide was used in all five fumigated vineyards at a rate of 560 to $670 \mathrm{~kg} \cdot \mathrm{ha}^{-1}$.

We established a series of three trap cultures from field-collected grapevine roots on the roots of potted sudangrass (Sorghum vulgare (1993). A shovel was used to collect about 0.3 $\mathrm{L}$ of grapevine fine roots (roots 1 to $2 \mathrm{~mm}$ in diameter) at a soil depth of 0.3 to $0.6 \mathrm{~m}$ from five randomly selected grapevines in each vineyard. Vineyards were sampled in Fall 2001. Grapevine fine roots, along with rhizosphere soil, were chopped into 1 to $2 \mathrm{~cm}$ segments and mixed with sand, which was autoclaved for 1 hour and cooled before incorporation into trap cultures. The root and sand mixture was divided among four $10-\mathrm{cm}$-diameter pots for each vineyard and sown with about 30 Sudan grass seeds per pot. Sudan grass was fertilized weekly with Hoagland's nutrient solution with 0.25 -strength P.

Precautions were taken to avoid cross-contamination among trap cultures. Replicate pots (four per vineyard) were randomly arranged on one greenhouse bench within about $40 \mathrm{~cm}$ of each other. Individual pots were hand-watered using a watering can to prevent water from splashing among pots. On the same greenhouse bench (about $1 \mathrm{~m}$ from the trap cultures), rooted grapevine scion cuttings (rooted in sterile, soilless potting mix) from a separate experiment served as noninoculated control plants, due to greenhouse space constraints. These noninoculated grapevines were monitored for the presence of AM fungi throughout all propagation cycles of the trap cultures and found to lack mycorrhizal colonization.

A single trap culture propagation cycle lasted for about 4 months. At the end of each propagation cycle, we cut the shoots of the Sudan grass plants and sowed new Sudan grass seeds, about 30 per pot, in the same pot. At the end of three consecutive propagation cycles, roots and soil were harvested and stored in sealed plastic bags at $4{ }^{\circ} \mathrm{C}$ until AM fungal spores could be identified. Spores were extracted from a $100-\mathrm{cm}^{3}$ subsample of soil by wet-sieving and sucrose centrifugation (Daniels and Skipper, 1982). The spores were Pers.) using the procedure of Morton et al. viewed with dissecting and compound microscopes and identified to the species level based on spore color, size, surface ornamentation, and wall structure using the species descriptions of Schenck and Pérez (1990).

\section{Mycorrhizal colonization and root biomass of grapevine nursery stock}

Nursery stock. We examined two types of dormant nursery stock, field-grown benchgrafts and potted benchgrafts, of Vitis vinifera L. 'Cabernet Sauvignon' (clone 8) grafted to three rootstocks: 101-14 (V. riparia Michx. $\mathrm{X}$ V. rupestris Scheele), $110 \mathrm{R}$ (V. berlandieri Planch. X V. rupestris Scheele), and St. George (V. rupestris Scheele). In California grapevine nurseries, there are two main propagation methods that result in production of grapevine material in the form of field-grown benchgrafts or potted benchgrafts. Dormant benchgrafts rooted in field soil in an open-ground nursery are referred to as field-grown benchgrafts. Once they go dormant, their shoots are pruned back and they are lifted from the field soil with a U-shaped digger that cuts the roots to a length of about $15 \mathrm{~cm}$. They are washed and kept in plastic bags full of damp wood chips in cold storage until they are shipped to growers (within 4 months). Dormant benchgrafts rooted in sterile potting mix in pots are referred to as potted benchgrafts. Once they go dormant, their shoots are pruned back. They remain in the pots they were rooted in and are shipped to growers with whole, dormant root systems.

We obtained field-grown benchgrafts and potted benchgrafts from two different California nurseries (neither nursery used both propagation methods). Field-grown benchgrafts were propagated in sandy loam soil (fumigated with methyl bromide about 2 months before planting) in a nursery located in Bakersfield, Calif. (about $180 \mathrm{~km}$ north of Los Angeles, Calif.). The Bakersfield nursery production blocks are surrounded by commercial vineyards and orchards. Potted benchgrafts, propagated in sterile potting mix (containing peatmoss, perlite, and vermiculite), were maintained in pots placed on wooden benches in a nursery located in Hughson, Calif. (about $160 \mathrm{~km}$ east of San Francisco, Calif.). The Hughson nursery is surrounded by commercial orchards and cattle grazing land.

Experimental design. Both types of benchgrafts were planted in 4-L pots with sterile potting mix in February 2002 and grown in the greenhouse for 7 months. Potting mix consisted of a 1:1:1 ratio of peatmoss, perlite, and Supersoil by volume (Rod McClellan Co., South San Francisco, Calif.) (peatmoss, ground fir bark, redwood compost, sand, 2-4-2 slow release fertilizer, oyster shell flour, and ground dolomite), and was autoclaved for $1 \mathrm{~h}$. Plants were arranged in a split-plot design on two benches that served as blocks. Benchgraft type was the mainplot treatment. Rootstock was the subplot treatment. Replicate plants (36 per rootstock per benchgraft type) were arranged as randomized complete blocks within mainplots of each block. Experimental treatments included all possible combinations of rootstock and benchgraft type, giving a total 


\begin{tabular}{|c|c|c|c|c|c|c|c|c|c|c|c|}
\hline \multirow[b]{2}{*}{ Arbuscular mycorrhizal fungi } & \multicolumn{5}{|c|}{ Fumigated vineyard } & \multicolumn{5}{|c|}{ Nonfumigated vineyard } & \multirow{2}{*}{$\begin{array}{c}\text { No. of } \\
\text { observations }\end{array}$} \\
\hline & M1 & N1 & So1 & So 2 & So3 & M2 & M3 & $\mathrm{N} 2$ & $\mathrm{~S} 1$ & $\mathrm{~S} 2$ & \\
\hline Entrophospora infrequens (Hall) Ames \& Schneider & & & & & & + & & & & & 1 \\
\hline Glomus aggregatum Schenck \& Smith emend. Koske & + & + & & + & + & & & + & & & 5 \\
\hline Glomus claroideum Schenck \& Smith & & + & & & & + & + & + & & & 4 \\
\hline Glomus clarum Nicolson \& Schenck & + & & & & + & + & & & & & 3 \\
\hline Glomus etunicatum Becker \& Gerd. & + & + & & + & & + & & & + & + & 6 \\
\hline Glomus fasciculatum (Thaxter) Gerd. \& Trappe emend. Walker and Koske & & & & & & + & & + & & & 2 \\
\hline Glomus fistulosum Skou \& Jakobsen & & & & & & & & + & & & 1 \\
\hline Glomus geosporum (Nicolson \& Gerd.) Walker & & & & + & & & & & + & & 2 \\
\hline Glomus leptotichum Schenck \& Smith & & & & & & & & + & & + & 2 \\
\hline Glomus microaggregatum Koske, Gemma \& Olexia & & & & & & & & & & + & 1 \\
\hline Glomus mosseae (Nicol. \& Gerd.) Gerd. \& Trappe & & & + & & + & & & & & & 2 \\
\hline Glomus pulvinatum (P. Henn.) Trappe \& Gerd. & & & & & & & + & + & & & 2 \\
\hline Glomus scintillans Rose \& Trappe & & & & & + & & + & & + & + & 4 \\
\hline Glomus sinuosum (Gerd. \& Bakshi) Almeida \& Schenck & + & & & & & & + & & & & 2 \\
\hline Glomus spurcum Pfeiffer, Walker \& Bloss & & & & & & & & & + & & 1 \\
\hline Glomus sp1 & & & & & & & & & + & & 1 \\
\hline Glomus sp2 & & & & & & & & & & + & 1 \\
\hline Glomus sp3 & & & & & & + & & & & & 1 \\
\hline Paraglomus occultum Morton \& Redecker & + & + & + & + & + & + & + & + & + & + & 10 \\
\hline Total no. of species in each vineyard & 5 & 4 & 2 & 4 & 5 & 7 & 5 & 7 & 6 & 6 & \\
\hline
\end{tabular}

${ }^{\mathrm{z}}$ Vineyards: $\mathrm{M}=$ Mendocino County; $\mathrm{N}=$ Napa County; $\mathrm{S}=$ San Joaquin County; So = Sonoma County.

of six treatments. Plants were fertilized weekly with Hoagland's nutrient solution with 0.25 strength P. Before plants were harvested, two replicate plants of 101-14 potted benchgrafts died, resulting in a slightly lower sample size for this treatment.

Mycorrhizal colonization and root biomass. After 7 months of growth in pots in the greenhouse, a subsample of fresh, new fine roots initiated from dormant roots was selected from each replicate plant and stained using the method of Koske and Gemma (1989). Mycorrhizal colonization (percent root length) by AM fungal structures was estimated using the grid-line intersect method (Giovannetti and Mosse, 1980). Mycorrhizal colonization was expressed as the percentage of intersects where AM fungal structures were present out of the total number of intersects examined (100 intersects) for an average of three grid rearrangements of the same subsample $(0.75$ $\mathrm{g}$ of fresh roots). Mycorrhizal colonization per 100 intersects was adjusted for percent root length, where root length was estimated from 100 intersect counts using the method of Newman (1966). Remaining roots were washed, oven-dried $\left(60{ }^{\circ} \mathrm{C}, 7 \mathrm{~d}\right)$, and weighed.

Subsamples (about $1 \mathrm{~g}$ per replicate plant) of new roots from each treatment (rootstock $x$ benchgraft type combination) were chopped and mixed with sterile sand to establish trap cultures (as described above). Mycorrhizal spores were extracted from every trap culture. However, there were not enough fresh spores with diagnostic morphological characteristics to mount on slides for identification.

Statistical analysis. An analysis of variance was used to determine the effects of benchgraft type and rootstock on mycorrhizal colonization and root biomass. A log transformation was performed on all mycorrhizal colonization and root biomass data before analysis to reduce heterogeneity of variance. The SAS Mixed procedure (SAS Institute, Inc., Cary, N.C.) was used for a split-plot design, treating benchgraft type, rootstock, and their interactions as fixed effects. Block effects and the interactions of block with benchgraft type and rootstock were treated as random effects.

\section{Results}

Survey of AM fungal communities in fumigated and nonfumigated vineyards. In 10 vineyards, we identified 19 AM fungal species, including three undescribed species of Glomus (Table 2). There were no obvious patterns in geographic distribution of AM fungi. All but two species, Paraglomus occultum (formerly known as Glomus occultum Walker) and Entrophospora infrequens, were in the genus Glomus. Paraglomus occultum was the only species present in trap cultures from all 10 vineyards. Glomus etunicatum was the second most common species, followed by Gl. aggregatum, Gl. claroideum, Gl. scintillans, and Gl. clarum. Of the 19 species identified, 13 were found in only one or two vineyards.

None of the vineyards lacked AM fungal spores, but the species composition of the spores was different among the vineyards (Table 2). In nonfumigated vineyards, the total number of species identified ranged from five to seven per vineyard, while in fumigated vineyards the total ranged from two to five. A total of 18 species were found in the nonfumigated vineyards, while only nine species were found in the fumigated vineyards. Of the nine species identified in the fumigated vineyards, only one species, Gl. mosseae, was not found in any of the nonfumigated vineyards. The most uncommon AM fungal species, those identified from only one vineyard, were all found in nonfumigated vineyards.

Mycorrhizal colonization and root biomass

Table 3. Results of ANOVA of effects of benchgraft type, rootstock, and their interaction on mycorrhizal colonization and root biomass of dormant grapevine nursery stock.

\begin{tabular}{lrrrrr}
\hline & \multicolumn{2}{c}{$\begin{array}{c}\text { Mycorrhizal colonization } \\
\text { (\% root length) }\end{array}$} & & \multicolumn{2}{c}{$\begin{array}{c}\text { Root biomasss } \\
(\mathrm{g})\end{array}$} \\
\cline { 2 - 3 } \cline { 5 - 6 } Source & $\mathrm{F}$ & $P>\mathrm{F}$ & & $\mathrm{F}$ & $P>\mathrm{F}$ \\
\hline Benchgraft & 49.66 & 0.0001 & & 3.24 & 0.3424 \\
Rootstock & 0.14 & 0.8731 & & 57.51 & 0.0001 \\
Benchgraft $\times$ rootstock & 1.02 & 0.4037 & & 24.03 & $<0.0001$ \\
\hline
\end{tabular}

of grapevine nursery stock. There was a significant effect of benchgraft type on mycorrhizal colonization of new roots initiated from field-grown benchgrafts and potted benchgrafts (Table 3). Mycorrhizal colonization of roots initiated from field-grown benchgrafts $(22.8 \%)$ was significantly higher than that of potted benchgrafts $(3.6 \%$, Table 4$)$. Analysis of variance detected no significant differences in mycorrhizal colonization among rootstocks and there was no effect of the benchgraft $x$ rootstock interaction (Table 3 ).

Total root biomass was not significantly different between field-grown and potted benchgrafts (Table 3 ). There were significant differences in root biomass among rootstocks. The interaction of benchgraft type and rootstock had a significant effect on root biomass. This is likely due to the disproportionately high root biomass of St. George potted benchgrafts (32.8 g) compared to the low root biomass of 101-14 and 110R potted benchgrafts (9.8 g and $9.4 \mathrm{~g}$, respectively, Table 4).

\section{Discussion}

Of the 19 AM fungal species identified in this study, 17 were in the genus Glomus. Similarly, a previous survey of California vineyards found seven of eight identified AM fungal species were in the genus Glomus (Menge et al., 1983). Results differed from that of Menge et al. (1983) in the total number of species identified and in the frequency of occurrence. Among the eight AM fungal species identified by Menge et al. (1983), Gl. fasciculatum, Gl. macrocarpum Tul. \& Tul., and $G l$. sinuosum (formerly known as Sclerocystis sinuosa Gerd. 
Table 4. Mycorrhizal colonization and root biomass of field-grown and potted benchgrafts of Vitis vinifera 'Cabernet Sauvignon' on three rootstocks (101-14, 110R, and St. George). Means followed by different letters are significant at $P<0.05$, Tukey's test.

\begin{tabular}{lcr}
\hline & $\begin{array}{c}\text { Mycorrhizal } \\
\text { colonization } \\
\text { (\% root length) }\end{array}$ & $\begin{array}{c}\text { Root } \\
\text { biomass } \\
(\mathrm{g})\end{array}$ \\
Source & & $18.0 \mathrm{a}$ \\
\hline Benchgraft & $22.8 \mathrm{a}$ & $17.5 \mathrm{a}$ \\
$\quad$ Field-grown $(\mathrm{n}=108)$ & $3.6 \mathrm{~b}$ & $13.2 \mathrm{~b}$ \\
Potted $(\mathrm{n}=106)$ & & $12.9 \mathrm{~b}$ \\
Rootstock & $12.3 \mathrm{a}$ & $27.0 \mathrm{a}$ \\
101-14 $(\mathrm{n}=70)$ & $15.2 \mathrm{a}$ & $16.4 \mathrm{a}$ \\
110R $(\mathrm{n}=72)$ & $12.3 \mathrm{a}$ & $16.4 \mathrm{a}$ \\
St. George $(\mathrm{n}=72)$ & & $21.3 \mathrm{a}$ \\
Benchgraft $\times$ rootstock interaction & & $9.8 \mathrm{~b}$ \\
Field-grown & $21.0 \mathrm{a}$ & $9.4 \mathrm{~b}$ \\
$101-14(\mathrm{n}=36)$ & $25.6 \mathrm{a}$ & $32.8 \mathrm{a}$ \\
$110 \mathrm{R}(\mathrm{n}=36)$ & $21.9 \mathrm{a}$ &
\end{tabular}

\& Bakshi) were the most common. In the 10 vineyards we surveyed, Gl. macrocarpum was not identified, while Gl. fasciculatum and $G l$. sinuosum were present but uncommon. Some AM fungal species identified by Menge et al. (1983) were not found in the vineyards we surveyed. Some of the differences between studies may be due to the fact that we used a series of three consecutive trap cultures, while Menge et al. (1983) used a single trap culture. Each successive trap culture is thought to encourage sporulation by additional AM fungal species (Stutz and Morton, 1996). Another possible reason for differences between studies is that the vineyards we sampled were in different counties, with the exception of San Joaquin County. However, given that no obvious geographic patterns in the species present among our vineyard sites were found, it seems unlikely that sampling different regions of the state contributed heavily to the identification of more AM fungal species.

AM fungal species identified on grapevines in California by our research and by that of Menge et al. (1983) have also been identified in grape-growing regions in other parts of the world. Nappi et al. (1985) reported Gl. fasciculatum and Gl. microcarpum Tul. \& Tul. to be the most common species, followed by $G l$. macrocarpum and $G l$. mosseae in six vineyards in Italy. Karagiannidis et al. (1997) found Gl. mosseae and Gl. macrocarpum were the most common fungi found in a vineyard in Greece.

Paraglomus occultum, which was identified in trap cultures from all 10 vineyards, is known as an aggressive colonizer and as a common contaminant of greenhouse trap cultures. Although contamination was checked for in the greenhouse study and precautions were taken to prevent cross-contamination among trap cultures, the possibility of contamination by $P$. occultum cannot be excluded.

The AM fungal community composition varied among the vineyards examined. Differences in AM fungal community composition may be due to differences in host plant species in each vineyard. In addition to grapevines, other potential mycorrhizal hosts that occupy the vineyard floor include weeds and cover crops. If the AM fungal species hosted by weeds and cover crops also colonize grapevines, differences in weed species composition and in cover crops maintained among the vineyards surveyed may contribute to differences in the AM fungi identified from the grapevine roots. In a Central Coast California vineyard, cover crops of Secale cereale 'Merced rye' and X Triticosecale 'Trios 102' shared four AM fungal species in common, two of which were also identified on adjacent grapevines (Baumgartner et al., 2004). In annual cropping systems, crop rotation has been shown to be associated with changes in the AM fungal community (Hendrix et al., 1995; Kurle and Pfleger, 1996). Species composition of AM fungi has also been shown to vary beneath different plant species in natural plant communities, suggesting that AM species composition is host-dependent (Bever et al., 1996; Eom et al., 2000; Johnson et al., 1992). Soil types and management practices, such as $\mathrm{P}$ fertilization, pesticide applications, and tillage, may also influence species composition (Kurle and Pfleger, 1996).

The five fumigated vineyards surveyed were $<2$ years old. The fact that none of them lacked AM fungi was not a surprise, given that Menge et al. (1983) found that grapevines planted in fumigated soil were colonized by AM fungi within 15 months of planting. Based on our results, AM fungal communities in fumigated vineyards were less diverse, in terms of total number of AM species identified. Without knowledge of their AM fungal communities at the time of vineyard establishment, it is unknown whether changes occurred in species composition over time or if differences in AM fungal community composition are a function of fumigation.

Nursery stock may be an important source of AM fungi for new vineyards, especially those established on fumigated sites. Our results showed that new roots initiated from both field-grown benchgrafts and potted benchgrafts were colonized by AM fungi after growth in the greenhouse for 7 months. However, mycorrhizal colonization of new roots initiated from potted benchgrafts was significantly lower than that of field-grown benchgrafts. Since both types of benchgrafts were grown under the same conditions, differences in mycorrhizal colonization of their new roots were likely due to mycorrhizal colonization potential of their dormant roots. Differences in rooting media used at the nurseries during propagation may be one reason for differences in mycorrhizal colonization. Higher mycorrhizal colonization of field-grown benchgrafts may be due to the presence of AM fungal propagules that survived fumigation in the soil they were planted in. Fumigation kills most AM fungal inoculum at the soil surface, but AM propagules that survive at lower soil depths may serve as inoculum for recolonization of surface soil (An et al., 1990). Also, soil fumigation is rarely uniform with depth due in part to nonuniform distribution of soil organic matter, which decreases the efficacy of soil fumigants (Menge, 1982). In contrast, potted benchgrafts were propagated in sterile potting mix at the nursery, which was initially free of AM fungal inoculum. Wind-blown spores from adjacent agricultural crops are likely the main source of primary inoculum (inoculum that first colonizes roots). In addition, peatmoss in nursery potting mix has been reported to decrease development of AM fungi (Linderman and Davis, 2003; Schubert et al., 1990). Thus, field-grown benchgrafts probably had a higher chance of becoming colonized by AM fungi than potted benchgrafts.

Differences in planting densities of the two types of benchgrafts may also contribute to the difference in mycorrhizal colonization. Fieldgrown benchgrafts are propagated directly in field soil at very concentrated planting densities (plants are about $5 \mathrm{~cm}$ apart). A single spore that colonizes a field-grown benchgraft during propagation can result in colonization of more than one benchgraft; extraradical hyphae can grow from the roots of one benchgraft to the roots of adjacent benchgrafts. The extraradical hyphal network is thought to be responsible for more rapid root colonization than that initiated by germinating AM fungal spores (Jasper et al., 1989; Read, 1992). In contrast, potted benchgrafts were propagated in the nursery in individual pots; a single wind-blown AM fungal spore could result in colonization of only one benchgraft.

There were no significant differences in mycorrhizal colonization among the three rootstocks examined, suggesting that rootstock may not have a strong influence on colonization levels of young grapevines. Linderman and Davis (2001) found small differences in mycorrhizal colonization among seven rootstocks and rooted grapevine cultivars inoculated with Gl. intraradices, a mixture of Gl. mosseae and Gig. rosea, or a mixture of Glomus species indigenous to Oregon vineyard soils. Differences in mycorrhizal colonization among rootstocks have been reported in several other studies (Bavaresco et al., 2000; Bavaresco and Fogher, 1996; Karagiannidis et al., 1997; Schreiner, 2003). However, the results regarding which specific rootstock had the highest level of mycorrhizal colonization were not consistent across studies, suggesting that rootstock effects on mycorrhizal colonization may be influenced by factors other than plant 
genotype, such as rootstock-scion interactions, soil fertility, soil $\mathrm{pH}$, or the species of AM fungi present (Schreiner, 2003).

\section{Conclusions}

In natural ecosystems, AM fungi play an important role in maintaining ecosystem function and productivity (Francis and Read, 1994; Hart and Klironomos, 2002; van der Heijden et al., 1998). Since specific AM fungi differ widely in their roles in natural ecosystems, low species diversity may decrease their individual contributions (Helgason et al., 1998). In agricultural ecosystems, intensive cultivation has been shown to alter AM fungal species composition and reduce the diversity of AM fungal communities (Miller et al., 1985; Smith and Read, 1997). However, the impacts of these changes on crop production have not been adequately studied. Crop management and soil factors affect the composition of the AM fungal community, which in turn may influence crop productivity (Hendrix et al., 1995; Kurle and Pfleger, 1996). Based on our results, nonfumigated vineyards appear to have a slightly more diverse AM fungal community than fumigated vineyards. It is not known whether these differences affect grapevine productivity.

There are two approaches to establishing and maintaining AM fungal populations in agricultural ecosystems: inoculation with selected AM fungal species or adoption of field practices that maximize indigenous populations of AM fungi (Smith and Read, 1997). In new vineyards, inoculation with commerciallyavailable AM fungi is labor-intensive and expensive. Based on our results, field-propagated grapevine nursery stock is colonized by AM fungi. Assuming our results apply to new roots initiated in field soil, field-grown benchgrafts may be slightly better suited, with more AM fungal propagules in their dormant roots, for establishing vineyards in fumigated soil than potted benchgrafts. Planting vineyards with field-grown benchgrafts and adopting vineyard floor management practices, such as cover cropping, that maximize mycorrhizal colonization of grapevine roots may be a more pragmatic approach to enhancing populations of AM fungi than inoculation with commercially-available AM fungi.

\section{Literature Cited}

An, Z.Q., J.H. Grove, J.W. Hendrix, D.E. Hershman and G. T. Henson. 1990. Vertical distribution of endogonaceous mycorrhizal fungi associated with soybean, as affected by soil fumigation. Soil Biol. Biochem. 22:715-719.

Bavaresco, L., E. Cantù, and M. Trevisan. 2000. Chlorosis occurrence, natural arbuscular-mycorrhizal infection and stilbene root concentration of ungrafted grapevine rootstocks growing on calcareous soil. J. Plant Nutr. 23:1685-1997.

Bavaresco, L. and C. Fogher. 1996. Lime-induced chlorosis of grapevine as affected by rootstock and root infection with arbuscular mycorrhiza and Pseudomonasfluorescens. Vitis
35:119-123

Baumgartner, K., R F. Smith, and L. Bettiga. 2004. Weed control and cover crop management affect mycorrhizal colonization of grapevine roots and arbuscular mycorrhizal fungal spore populations in a California vineyard. Mycorrhiza (In press).

Bever, J.D., J.B. Morton, J. Antonovics, and P.A. Schultz. 1996. Host-dependent sporulation and species diversity of arbuscular mycorrhizal fungi in a mown grassland. J. Ecol. 84:71-82.

Biricolti, S., F. Ferrini., E. Rinaldelli, I. Tamantini, and N. Vignozzi. 1997. VAM fungi and soil lime content influence rootstock growth and nutrient content. Amer. J. Enol. Viticult. 48:93-99.

Daft, M.J. and B.G. Hogarth. 1983. Competitive interactions amongst four species of Glomus on maize and onion. Tran. Br. Mycol. Soc. 80:339-345

Daniels, B.A., and H.D. Skipper. 1982. Methods for the recovery and quantitative estimation of propagules from soil, p. 29-35. In: N.C. Schenck (eds.). Method and principles of mycorrhizal research. Amer. Phytopathol. Soc., St. Paul, Minn.

Deal, D.R., C.W. Boothroyd, and W.F. Mai. 1972. Replanting of vineyards and its relationship to vesicular-arbuscular mycorrhiza. Phytopathology 62:172-175.

Eom, A.-H., D.C. Hartnett, and G.W.T. Wilson. 2000. Host plant species effects on arbuscular mycorrhizal fungal communities in tallgrass prairie. Oecologia 122:435-444.

Francis, R. and D.J. Read. 1994. The contributions of mycorrhizal fungi to the determination of plant community structure. Plant Soil. 159:11-25.

Giovannetti, M. and B. Mosse. 1980. An evaluation of techniques for measuring vesicular arbuscular mycorrhizal infection in roots. New Phytol. 84:489-500.

Hart, M.M. and J.N. Klironomos. 2002. Diversity of arbuscular mycorrhizal fungi and ecosystem functioning, p 225-242. In: M.G.A. van der Heijden and I.R. Sanders (eds.). Mycorrhizal ecology. Springer-Verlag, New York.

Helgason, T., T.J. Daniell, R. Husband, A.H. Fitter, and J.P.W. Young. 1998. Ploughing up the wood-wide web? Nature 394:431.

Hendrix, J.W., B.Z. Guo, and Z.Q. An. 1995. Divergence of mycorrhizal fungal communities in crop production systems. Plant Soil. 170:131-140.

Jasper, D.A., L.K. Abbott, and A.D. Robson. 1989. Soil disturbance reduces the infectivity of external hyphae of vesicular-arbuscular mycorrhizal fungi. New Phytol. 112:93-99.

Johnson, N.C., D. Tilman, and D. Wedin. 1992 Plant and soil controls on mycorrhizal fungal community. Ecology 73:2034-2042.

Karagiannidis, N. and N. Nikolaou. 2000. Influence of arbuscular mycorrhizae on heavy metal $(\mathrm{Pb}$ and $\mathrm{Cd}$ ) uptake, growth, and chemical composition of Vitis vinifera L. (cv. Razaki). Amer. J. Enol. Viticult. 51:269-275.

Karagiannidis, N., D. Velemis, and N. Stavropoulos. 1997. Root colonization and spore population by VA-mycorrhizal fungi in four grapevine root stocks. Vitis 36:57-60.

Koomen, I., C. Grace, and D.S. Hayman. 1987. Effectiveness of single and multiple mycorrhizal inocula on growth of clover and strawberry plants at two soil pHs. Soil. Biol. Biochem. 19:539-544.

Koske, R.E. and J.N. Gemma. 1989. A modified procedure for staining roots to detect VA mycorrhizas. Mycol. Res. 92:486-505.

Kurle, J.E. and F.L. Pfleger. 1996. Management influences on arbuscular mycorrhizal fungal species composition in a corn-soybean rotation. Agron. J. 88:155-161.

Linderman, R.G. and E.A. Davis. 2001.Comparative response of selected grapevine rootstocks and cultivars to inoculation with different mycorrhizal fungi. Amer. J. Enol. Viticult. 52:8-11.

Linderman, R.G. and E.A. Davis. 2003. Soil amendment with different peatmosses affects mycorrhizae of onion. HortTechnology 13:285-289.

Menge, J.A. 1982. Effect of soil fumigants and fungicides on vesicular-arbuscular fungi. Phytopathology 72:1125-1131.

Menge, J.A., D.J. Raski, L.A. Lider, E.L. V. Johnson, N.O. Jones, J.J. Kissler, and C.L. Hemstreet. 1983. Interactions between mycorrhizal fungi, soil fumigation, and growth of grapes in California. Amer. J. Enol. Viticult. 34:117-121.

Miller, D.D., P.A. Domoto, and C. Walker. 1985. Mycorrhizal fungi at eighteen apple rootstockplantings in the United States. New Phytol. 100:379-391.

Morton, J.B., S.P. Bentivenga, and W.W. Wheeler. 1993. Germplasm in the international collection of arbuscular and vesicular-arbuscular mycorrhizal Fungi (INVAM) and procedures for culture development, documentation and storage. Mycotaxon 48:491-528.

Nappi, P., R. Jodice, A. Luzzati, and L. Corino. 1985. Grapevine root system and VA mycorrhizae in some soils of Piedmont (Italy). Plant Soil. 85:205-210.

Newman, E.I. 1966. A method of estimating the total length of root in a sample. J. Appl. Ecol. 3:139.

Possingham, J.V. and J. Groot-Obbink. 1971. Endotrophic mycorrhiza and the nutrition of grape vines. Vitis 10:120-130.

Read, D.J. 1992. The mycorrhizal mycelium, p. 102-123. In: M.F. Allen (ed.). Mycorrhizal functioning. Chapman and Hall, London, U.K.

Schellenbaum, L., G. Berta, F. Ravolanirina, B. Tisserant, S. Gianinazzi, and A.H. Fitter. 1991. Influence of endomycorrhizal infection on root morphology in a micropropagated woody plant species (Vitis vinifera L.). Ann. Bot.. 68:135-141.

Schenck, N. C., and Y. Pérez. 1990. Manual for the identification of VA mycorrhizal fungi. Synergistic Publ., Gainesville, Fla.

Schreiner, P. R. 2003 Mycorrhizal colonization of grapevine rootstocks under field conditions. Amer. J. Enol. Viticult. 54:143-149.

Schubert, A., S. Cammarata, and I. Eynard. 1988. Growth and root colonization of grapevines inoculated with different mycorrhizal endophytes. HortScience 23:302-303.

Schubert, A., M. Mazzitelli, O. Aricusso, and I. Eynard. 1990. Effects of vesicular-arbuscular mycorrhizal fungi on micropropagated grapevines: influence of endophyte strain, P fertilization and growth medium. Vitis 29:5-13.

Smith, S.E. and D.J. Read. 1997. Mycorrhizal symbiosis. Academic Press, London, U.K.

Stutz, J.C. and J.B. Morton. 1996. Successive pot cultures reveal high species richness of arbuscular endomycorrhizal fungi in arid ecosystems. Can. J. Bot. 74:1883-1889.

van der Heijden, M.G.A., J.N. Klironomos, M. Ursic, P. Moutoglis, R. Streitwolf-Engel, T. Boller, A. Wiemken, and I.R. Sanders. 1998. Mycorrhizal fungal diversity determines plant diversity, ecosystem variability and productivity. Nature 396:69-72. 